\title{
Temperament and character profiles of medical students associated with tolerance of ambiguity and perfectionism
}

\author{
Janni Leung $^{\text {Corresp., } 1}$, C. Robert Cloninger ${ }^{2}$, Barry A Hong ${ }^{2}$, Kevin M Cloninger $^{3}$, Diann S Eley ${ }^{1}$ \\ ${ }^{1}$ The University of Queensland, Brisbane, Australia \\ 2 Department of Psychiatry, School of Medicine, Washington University, St. Louis, United States \\ 3 The Anthropedia Foundation, St. Louis, United States \\ Corresponding Author: Janni Leung \\ Email address: j.leung1@uq.edu.au
}

Background. Certain personal attributes, such as perfectionism and tolerance of ambiguity, have been identified as influential in high achieving students. Medical students have been identified as high achievers and perfectionistic, and as such may be challenged by ambiguity. Medical students undertake a long and challenging degree. Personality has been shown to influence the well-being and coping and may equip some students to better cope with challenges. This paper examines the association between temperament and character personality profiles with measures of tolerance of ambiguity and with both adaptive and maladaptive constructs of perfectionism.

Methods. A self-report questionnaire collected data on a sample of 808 Australian medical students in 2014 and 2015. Personality was measured using the Temperament and Character Inventory (TCIR-140) and classified traits as profiles using a latent class analysis. Two profiles were found. Profile 1 was characterized by low-average levels of Harm Avoidance, and high to very high levels of Persistence, SelfDirectedness and Cooperativeness. Moderately-high levels of Harm Avoidance and high levels of Persistence, Self-Directedness and Cooperativeness characterized Profile 2. Moderation regression analyses were conducted to examine the association between the personality profiles with levels of Tolerance of Ambiguity (MSAT-II), Perfectionism-Concern over Mistakes and Perfectionism-High Standards (FMPS), considering demographic characteristics.

Results. Students with Profile 1 were higher in levels of Tolerance of Ambiguity, and Perfectionism-High Standards, and lower levels of Perfectionism-Concern over Mistakes compared to Profile 2. These findings remained statistically significant after adjusting for age and gender. A significant personality by age interaction on Tolerance of Ambiguity was found. While higher levels of Tolerance of Ambiguity were associated with older age overall, it remained low across age for students with a personality Profile 2.

Conclusions. A particular combination of personality traits was identified to be associated with low Tolerance of Ambiguity and high levels of maladaptive Perfectionism. An intolerance of ambiguity and over concern about mistakes maybe maladaptive and underlie vulnerability to stress and poor coping. The psychobiological model of personality provides insight into traits that are stable and those that can be self-regulated through education and training. The interaction between biological mechanisms and socio-cultural learning is relevant to a sample of medical students because it accounts for interaction of the biological or innate aspects of their personal development within an intense and competitive learning environment of medical school. 


\section{Temperament and character profiles of medical students}

2 associated with tolerance of ambiguity and perfectionism

3

4 Janni Leung ${ }^{1}$, C. Robert Cloninger ${ }^{2}$, Barry A Hong ${ }^{2}$, Kevin M Cloninger ${ }^{3}$, Diann S Eley ${ }^{1}$

5

$6 \quad{ }^{1}$ The University of Queensland, St Lucia, Australia

$7 \quad 2$ Department of Psychiatry, School of Medicine, Washington University, St. Louis, United

8 States

$9{ }^{3}$ The Anthropedia Foundation, St. Louis, United States

10

11 Corresponding Author:

12 Janni Leung ${ }^{1}$

13 The University of Queensland, St Lucia, QLD 4072, Australia

14

15 
16 Abstract

17

18 Background. Certain personal attributes, such as perfectionism and tolerance of ambiguity, have been identified as influential in high achieving students. Medical students have been identified as high achievers and perfectionistic, and as such may be challenged by ambiguity. Medical students undertake a long and challenging degree. Personality has been shown to influence the well-being and coping and may equip some students to better cope with challenges. This paper examines the association between temperament and character personality profiles with measures of tolerance of ambiguity and with both adaptive and maladaptive constructs of perfectionism. 25

Methods. A self-report questionnaire collected data on a sample of 808 Australian medical students in 2014 and 2015. Personality was measured using the Temperament and Character Inventory (TCIR-140) and classified traits as profiles using a latent class analysis. Two profiles were found. Profile 1 was characterized by low-average levels of Harm Avoidance, and high to very high levels of Persistence, Self-Directedness and Cooperativeness. Moderately-high levels of Harm Avoidance and high levels of Persistence, Self-Directedness and Cooperativeness characterized Profile 2. Moderation regression analyses were conducted to examine the association between the personality profiles with levels of Tolerance of Ambiguity (MSAT-II), Perfectionism-Concern over Mistakes and Perfectionism-High Standards (FMPS), considering demographic characteristics.

Results. Students with Profile 1 were higher in levels of Tolerance of Ambiguity, and Perfectionism-High Standards, and lower levels of Perfectionism-Concern over Mistakes compared to Profile 2 . These findings remained statistically significant after adjusting for age and gender. A significant personality by age interaction on Tolerance of Ambiguity was found. While higher levels of Tolerance of Ambiguity were associated with older age overall, it remained low across age for students with a personality Profile 2.

\section{Conclusions.}

A particular combination of personality traits was identified to be associated with low Tolerance 
47 over concern about mistakes maybe maladaptive and underlie vulnerability to stress and poor 48 coping. The psychobiological model of personality provides insight into traits that are stable and 49 those that can be self-regulated through education and training. The interaction between

50 biological mechanisms and socio-cultural learning is relevant to a sample of medical students 51 because it accounts for the interaction of the biological or innate aspects of their personal 52 development within an intense and competitive learning environment of medical school. 53 


\section{Introduction}

56 The health and well-being of medical students along with their successful progression through

57 medical training is an important concern to medical educators. High levels of stress, depression 58 and anxiety are increasingly noted in doctors and medical students, ${ }^{[1,2]}$ and are higher than their nonmedical peers in the general population ${ }^{[3]}$. In turn, this higher level of dysphoria may affect expressions of empathy, impair professional behaviour and contribute to burn-out and drop-out [4]. The many pressures and demands associated with medical training can drive students to excessive self-criticism, self-doubt and fear about making mistakes $[1,5,6]$.

Comprehensive reviews have recognised personality as an influencing factor on many aspects of medical students' successful and healthy progression through medical training ${ }^{[7,8]}$. The literature is clear that certain personality traits can influence or predict various aspects of academic performance, ${ }^{[9-13]}$ including subsequent performance in postgraduate training, ${ }^{[14]}$ subclinical competence, ${ }^{[15,16]}$ expression of empathy, ${ }^{[17,18]}$ subjective well-being, ${ }^{[19,20]}$ mental toughness, ${ }^{[21]}$ attitudes to work, burnout and stress, ${ }^{[5]}$ and career interests ${ }^{[22-24]}$.

The measurement of personality across these studies differ, primarily around variants of the Five-Factor Model (FFM). ${ }^{[25,26,27]}$ The Temperament and Character Inventory (TCI), developed by Cloninger, ${ }^{[28,29]}$ distinguishes between seven personality traits within the domains of temperament (Novelty Seeking, Harm Avoidance, Reward Dependence, Persistence), and character (Self-Directedness, Cooperativeness, Self-Transcendence). Japanese studies with medical students demonstrated positive associations between intrinsic academic motivation and the TCI's Persistence, Self-Directedness and Self-Transcendence, leading to better academic performance, ${ }^{[30]}$ and Jiang ${ }^{[31]}$ found positive associations between the TCI's Harm Avoidance and measures of anxiety. Resilience was shown to be strongly correlated with high levels of SelfDirectedness, Cooperativeness and Persistence and low Harm Avoidance in Australian medical residents ${ }^{[32]}$. Furthermore, several studies in the general population have shown that high SelfDirectedness and low Harm Avoidance are the strongest predictors of well-being and satisfaction 83 with life ${ }^{[33-35,36]}$. 
85 Importantly, the TCI provides insight into the combination of traits from a psychobiological 86 perspective identifying aspects of personality that are relatively stable (temperament traits), and

87 those that are more amiable to change through sociocultural learning (character traits). The

88 psychobiological model of personality suggests there is interaction between biological

89 mechanisms and learning over the development of an individual within the context of his/her environment. Heritable influences that refer to genetically inherited qualities are equally great on temperament and character but character plays the self-regulatory role, which is targeted in parenting, teaching, and coaching. Examining profiles or combinations of trait levels affords a more meaningful understanding of what drives individuals' behaviours and how they adapt to life situations ${ }^{[26]}$. The individual traits of a person must interact in a complex dynamic way to adapt to internal or external challenges ${ }^{[33,34]}$. This suggests that certain personality profiles are prone to being more or less vulnerable to adapting to and coping with these challenges. In addition to temperament and character, many other psychological attributes can influence one's capacity for coping and may influence well-being. Pertinent to medical students are the attributes of ambiguity tolerance and perfectionism ${ }^{[38-40]}$. We chose these attributes as proxy measures of capacity for coping and are discussed briefly below.

The early work by Budner showed that individuals with a low Tolerance of Ambiguity experience anxiety or stress when they perceive new or complex situations ${ }^{[41]}$. Geller provides a thoughtful perspective on Tolerance of Ambiguity among medical students ${ }^{[39]}$. She emphasises the ubiquitous place of ambiguity in medical practice and the need to understand the ramifications at both ends of the tolerance spectrum. Ambiguity tolerance exerts a strong influence on the attitudes and behaviours of medical students. In particular, low Tolerance of Ambiguity has been linked to higher perceived stress ${ }^{[42]}$ and higher rates of burnout ${ }^{[43]}$.

110 Socio-demographic characteristics such as sex and age are associated with individual differences 111 in ambiguity tolerance. Higher levels are found in men and older students, ${ }^{[42]}$ in leaders, ${ }^{[44]}$ and

112 in people willing to work in rural or underserved areas ${ }^{[45]}$. In contrast, low ambiguity tolerance

113 has been associated with negative attitudes to underserved groups of people, ${ }^{[45]}$ burnout in 114 primary care ${ }^{[46]}$ and emergency physicians, ${ }^{[47]}$ higher levels of stress in medical students, ${ }^{[42]}$ 115 and a fear of making mistakes ${ }^{[48]}$. Personality traits have also been associated with the way 
116 physicians deal with uncertainty and their diagnostic decision making [49], but little research has

117 investigated the relationship between temperament and character traits with Tolerance of

118 Ambiguity in medical students.

119

120 Perfectionism is a common characteristic of high achieving individuals and is prevalent in 121 medical students and physicians ${ }^{[50,51]}$. Perfectionism most commonly features the setting of

122 excessively high personal standards of performance ${ }^{[52]}$ which may have important benefits to 123 medical care such as attention to detail and a strong sense of responsibility [51]. Perfectionism

124 exists on a continuum and can be either healthy and adaptive or self-defeating and maladaptive

$125[40,53]$. The major distinction is that adaptive perfectionists have a higher acceptance to allow

126 minor flaws in their work and still accept it as successful. They are driven by meaningful goals

127 and striving for achievement. In contrast, maladaptive perfectionists are simply unable to accept

128 mistakes. They set standards so unrealistically high that instead of directing their goals toward

129 striving for achievement, they are driven by fear of failure which has implications for decision

130 making. Research by Enns ${ }^{[40]}$ found that medical students differed from arts students in aspects

131 of perfectionism. In medical students, adaptive perfectionism was correlated with academic

132 performance and levels of conscientiousness, whereas maladaptive perfectionism correlated with

133 symptoms of distress and levels of neuroticism which further predicted depression over time.

134 Similarly, the association between personality profiles and the different types of perfectionism in

135 medical students has not previously between examined.

137 The aim of this paper was to examine the relationship between personality profiles of medical

138 students and psychological attributes that may be indicative of coping with a challenging medical

139 degree. We examined the association between personality profiles with tolerance of ambiguity

140 and the two constructs of Perfectionism, (High Standards and Concern over Mistakes), and

141 whether the relationships differ by demographic characteristics. We hypothesised that there

142 would be significant relationships between medical student's personality profile and levels of

143 each coping attribute. We expected that students who fit in a personality profile that comprised a

144 temperament low in Harm Avoidance and high in Persistence, and a character high in Self

145 Directedness and Cooperativeness, would have high levels of ambiguity tolerance and adaptive 146 perfectionism. 
148 Materials \& Methods

149

150 Design

151 The study design is quantitative cross-sectional using a self-report questionnaire. Ethics was

152 approved by the Behavioural and Social Sciences Ethical Review Committee at The University 153 of Queensland. (Approval Number: 2015001895). Participants provided written consent which 154 was documented on the questionnaire and approved by this ethics committee.

156 Participants and setting

157 Data were collected in 2014 and 2015 at The University of Queensland School of Medicine, 158 Australia. The questionnaire was identical in both years and was accessed via an online link 159 (Survey Monkey()). Students were invited to complete the questionnaire via an email invitation 160 to access the link. The 2014 collection invited all students in the four-year medical program to 161 participate through an invitation to access the link on the student community website. However, 162 this method failed to reliably reach all students. In 2015 the data collection involved only Year 1 163 students who were invited to participate during a regularly scheduled activity. All participants 164 were graduate entry medical students and completed the survey only once. The overall response 165 rate was $62 \%$. The final sample size was $\mathrm{N}=808$. The mean age was 24.88 years $(\mathrm{SD}=4.00)$, 166 median age was $24(\mathrm{IQR}=5)$. The modal age was 23 , but the distribution was skewed to the right 167 (skewness $=2.87$ ), due to the mature age entry students. Due to the distribution, age was not able 168 to be analyzed as a continuous variable. Therefore, based on the mean value, the age variable 169 was split into under 25 years, and 25 year or older because this is largely in line with the phases 170 of training in the medical degree.

172 Measures

\section{Temperament and character personality profiles}

174 Personality profiles were measured using the 140-item Temperament and Character Inventory [28,

$175^{29}$. The four temperament traits measure basic emotional drives, are heritable and do not change

176 significantly over the life course. Novelty Seeking reflects a heritable bias observed as

177 exploratory activity in response to novelty, impulsiveness, and extravagance in approach to cues 
178 of reward. Harm Avoidance involves a heritable bias observed as anxiety proneness, and

179 pessimistic worry in anticipation of problems. Reward Dependence is behaviour in response to

180 cues of social reward and is observed as social sensitivity and dependence on approval by others.

181 Persistence is the maintenance of behaviour despite frustration, fatigue and reinforcement. It

182 reflects industriousness and determination. The three character traits are developmental and

183 influenced by learning, the environment and life experiences. Self-Directedness measures intra-

184 personal character strengths, such as being responsible, purposeful, goal-oriented and self-

185 confident. Cooperativeness measures inter-personal character strengths, such as tolerance,

186 empathy, and respectful acceptance of the opinions and behaviours of others. Self-transcendence

187 measures transpersonal character strengths. It quantifies the extent to which individuals conceive

188 themselves as integral parts of the universe as a whole.

189

190 The TCIR-140 uses a five point Likert scale ( $1=$ absolutely false to $5=$ absolutely true). Internal

191 reliability (Cronbach alphas) of each trait ranged from 0.86 to 0.89 for the character and 0.69 to

1920.91 for temperament scales. The scales are multifaceted with high and low descriptors of each

193 trait see ${ }^{[37]}$. Details on the interpretation of low and high scores of the seven TCI subscales are

194 available in Appendix A.

196 From the TCI subscales, two personality profiles were classified based on clusters of individuals

197 with distinctive combinations of the seven traits revealed in a latent profile analysis. Further

198 details of the classification methods are available in Appendix B. Profile 1 was characterized by

199 low to average levels of Harm Avoidance, and high to very high levels of Persistence, Self-

200 Directedness and Cooperativeness (see Figure 1), In comparison, Profile 2 was characterised by

201 average-high levels of Harm Avoidance and high levels of Persistence, Self-Directedness and

202 Cooperativeness, as determined by comparison to normal range percentiles of the population [63].

203 In other words, medical students in both profiles describe themselves as healthier and more

204 mature than average. However, the medical students in Profile 1 are even more confident and

205 resilient than the other medical students and the general population, whereas those in Profile 2

206 are slightly more anxious and worried than most people in the general population. 
209 Tolerance of ambiguity

210 The Multiple Stimulus Types Ambiguity Tolerance Scale-II (MSTAT-II) ${ }^{[55]}$ is based on the

211 theory that an individual's perception of ambiguity is an orientation ranging from attraction to

212 aversion toward stimuli that are uncertain, insoluble or unfamiliar. The MSTAT-II consists of 13

213 items and uses a Likert response scale of $1=$ definitely false to $5=$ definitely true. Items were

214 summed, with a low score indicating a low, and high score, a high Tolerance of Ambiguity,

215 alpha $=0.82$.

216

217 Perfectionism

218 Two dimensions of the Frost Multi-dimensional Perfectionism Scale (FMPS) ${ }^{[53,56]}$ were used;

219 Concern over Mistakes ( 8 items; maladaptive) is central to the concept of perfectionism and a

220 major component of other measures which tend toward psychological distress including

221 procrastination and fear of mistakes, and High Standards (5 items; adaptive) which reflects

222 positive and healthy striving toward goals. Each item was presented as a five point Likert scale

223 from $1=$ strongly disagree to $5=$ strongly agree. Items were summed to derive scores for the two

224 subscales, with higher scores indicative of higher levels of perfectionism. The alphas for each are

2250.89 and 0.80 respectively.

226

227 Analysis

228 Independent samples t-tests were conducted, with eta $(\eta)$ for assessing effect sizes, comparing

229 the means of the coping attributes (Tolerance of Ambiguity, perfectionism high standards and

230 concern over mistakes), by the two personality profiles. Generalized linear models were used to

231 examine the main effects of personality profile on the coping attributes after including age and

232 gender in the analysis. The coping attributes were the dependent variables in the models. In

233 addition, interaction terms between personality profile with age and gender were included to

234 examine if the association between profiles and the coping attributes differ by demographic

235 characteristics. All analyses were conducted using SPSS 24.

236

237 Results

238 Sample characteristics 
239 Descriptive statistics of the participants are presented in Table 1. Slightly over half were under

24025 years of age, $54.3 \%$ were male. These proportions are not different to the cohorts from which

241 our sample was taken. Over half of the students fit into personality Profile 1 (59.8\%).

242

243 The 25 or older age group had slightly higher level of Tolerance of ambiguity and perfectionism

244 high standards than the under 25 years group, though the effect sizes were very small (see Table

245 2). Males had slightly higher levels of Tolerance of Ambiguity but lower levels of perfectionism

246 concern over mistakes than female, though the effect sizes were very small. There were no

247 significant differences by Year of medical school, therefore it was not included in further

248 analyses.

249

250 Coping attributes by personality profiles

251 Independent t-tests results showed that students with the Profile 1 had significantly higher levels

252 of Tolerance of Ambiguity $(\mathrm{t}=12.73, \eta=.58, \mathrm{p}<.001)$, perfectionism high standards $(\mathrm{t}=6.02$,

$253 \eta=.21, \mathrm{p}<.001)$, and lower levels of Perfectionism-Concern over Mistakes $(\mathrm{t}=-11.19, \eta=.37$,

$254 \mathrm{p}<.001$; see Figure 2).

255

256 Results from the generalized linear models showed that personality profiles remained

257 significantly associated with Tolerance of Ambiguity, Perfectionism-Concern over Mistakes, and

258 Perfectionism-High Standards, after taking into consideration the age and gender of the students

259 (see Table 3). A significant Profile by age interaction was found on Tolerance of Ambiguity. The

260 association between profile and Tolerance of Ambiguity was stronger in the older age group.

261 That is, the positive effects of having personality Profile 1 on higher levels of Tolerance of

262 Ambiguity was especially significant for the students aged 25 years or older (see Figure 3).

263

264

\section{Discussion}

266 This study examined Tolerance of Ambiguity, and Perfectionism and their association with

267 temperament and character personality profiles in a sample of medical students. We found that

268 students with the combination of traits identified in Profile 1 (characterized by low to average

269 levels of Harm Avoidance, and high to very high levels of Persistence, Self-Directedness and 
270 Cooperativeness) had significantly higher levels of Tolerance of Ambiguity and lower levels of

271 Perfectionism-Concern over Mistakes compared to those in Profile 2 (characterized by average-

272 high levels of Harm Avoidance and high levels of Persistence, Self-Directedness and

273 Cooperativeness). We identified that students with the particular combinations of personality

274 traits fitting in Profile 2 are implied to be a risk of lower ability to cope in the medical setting. In

275 testing for moderation effects by age, our study highlighted that while Tolerance of ambiguity

276 may increase with age, it did not do so for students with personality Profile 2, for which

277 Tolerance of Ambiguity remained low across age.

278

279 The difference between the Profiles in Perfectionism-High Standards was slight with a small

280 effect size and suggests that medical students in general have high standards and strive for high

281 achievement. This concurs with Enns ${ }^{[40]}$ who found medical students to be significantly higher

282 in levels of Perfectionism-High Standards compared to general arts students. Across the whole

283 sample, irrespective of Profile, older students and males had higher levels of Tolerance of

284 Ambiguity ${ }^{[42]}$.

285

286 As noted in a previous study, ${ }^{[37]}$ both personality profiles are similar in the trend of their trait

287 levels and it is primarily the levels of two temperament and one character trait that differentiates

288 them. Looking at the two temperament traits; Persistence (higher in Profile 1) is strongly

289 associated with perfectionism and can contribute to maladaptive characteristics ${ }^{[54]}$. This is

290 because of the persistent need for perfection and drive to attain unreasonable standards, self-

291 criticism, and self-doubt is defeatist ${ }^{[40]}$. These feelings may lead to maladaptive behaviours such

292 as procrastination or even cheating. However, despite higher levels of Persistence, compared to

293 Profile 2, Profile 1 students still showed lower levels of maladaptive perfectionism (Concern

294 over Mistakes). This effect may be explained by the lower levels of another temperament trait,

295 Harm Avoidance. Low Harm Avoidance enables confidence and optimism along with a degree

296 of comfort with uncertainty. Along with very high Self-Directedness, portrayed as being

297 conscientiousness and goal directed, these two traits act to temper the potential harm of very high

298 Persistence. Rather than a collection of separate parts, these three traits, (low Harm Avoidance

299 and high Self-Directedness and Persistence) demonstrate that multiple dimensions of personality 
300 interact as components of a complex adaptive system ${ }^{[33,54]}$ to influence levels of perfectionism

$301{ }^{[40]}$ and ultimately through more effective coping and levels of resilience ${ }^{[32]}$.

302

303 This same combination of temperament and character traits (Profile 1) strengthens our

304 understanding of ambiguity tolerance. To put it in the context of our study, the ubiquitous

305 ambiguity present in medicine, ${ }^{[39]}$ implies a need for more consideration on how to address low

306 ambiguity tolerance and its possible association with stress, burnout, quality of patient care, $[42,43$,

$307{ }^{45]}$ and not surprisingly an over concern for mistakes ${ }^{[48]}$.

308

309 Our study design only allows us to suggest the utility of the knowing the associations we have

310 found in the data. Nevertheless, we posit that knowing you are low in Tolerance of Ambiguity,

311 or excessively concerned about mistakes may not be as helpful as understanding why you tend

312 towards those feelings and attitudes. As suggested by Epstein, ${ }^{[57]}$ understanding one's own

313 personality helps build self-awareness, to recognise when stressors occur, and self-reflection on

314 how to react or self-monitor one's feelings and coping response. Our study was only cross-

315 sectional and exploratory. A longitudinal prospective design would be the only way to determine

316 if a better understanding of one's personality heightens self-awareness and better equips them to

317 perceive and deal with challenges and hardships. It would also enable us to further examine how

318 personality and coping interacts overtime as the students age and transition into medical practice.

319 Our data is fed back to students, both individually on request, and in aggregate to help stimulate

320 an interest in reflecting on how they personally cope (or not), with what they find challenging in

321 medical school. Further research will follow students' through medical school to examine

322 changes in personality profiles and measures of coping attributes over time.

323

324 There are limitations to this study which include the inherent bias in self-report data collection

325 and the cross-sectional design with one medical school, which may reduce generalisability of our

326 results. The majority of respondents were in their first year of medicine, and therefore their

327 limited exposure to medical training may have influenced their responses. However, there was

328 no differences in the age or gender distribution among responders across the four years or

329 differences in individual TCI trait levels. Certainly this study should be repeated with other

330 medical student cohorts to see if profile patterns are similar. The present data are cross-sectional

Peer) reviewing PDF | (2019:01:34563:1:2:NEW 2 May 2019) 
331 so they do not demonstrate causal relations or the ability to change personality. However, other

332 experimental research shows that it is possible to help a person grow in self-awareness and

333 thereby change in personality and improve well-being [33,58,59]. Strengths of the study include a

334 large sample of students and the use of well validated measures of our variables.

335

336

337 Conclusions

338 This research identified a particular combinations of personality traits associated with low

339 Tolerance of Ambiguity and high levels of maladaptive Perfectionism. These findings have

340 implications for well-being in the medical setting, as they reduce the coping ability of medical

341 students in this challenging profession. The psychobiological model of personality provides

342 insight into traits that are stable and those that are amenable to self-regulation through learning,

343 hence can be targeted in education and training settings. The interaction between biological

344 mechanisms and socio-cultural learning is relevant to a sample of medical students because it

345 accounts for interaction of the biological or innate aspects of their personal development within

346 an intense and competitive learning environment of medical school. 


\section{References}

348

349 1. Firth-Cozens J. Doctors, their well-being, and stress. BMJ 2003; 326:670-671.

350

351 2. Dyrbye L, Shanafelt, TD. Systematic review of depression, anxiety and other indicators of

352 psychologic distress among US and Canadian medical students. Academic Medicine 2006;

353 81(4):354-73.

354

355

3. Dyrbye LN, Harper W. Durning SJ, Moutier C, Thomas MR, Stanford Massie Jr F, Eacker A, 356

Power DV, Szydlo DW, Sloan JA, Shanafelt TD. Patterns of distress in US medical students.

Medical Teacher 2011; 33:834-9.

358

359

4. Brazeau CMLR, Schroeder R, Rovi S, Boyd, L. Relationships Between Medical Student

360

Burnout, Empathy, and Professionalism Climate. Academic Medicine 2010; 85(10 Supplement):

361 S33-S36.

362

363

5. McManus I, Keeling A, Paice E. Stress, burnout and doctors' attitudes to work are determined

364

by personality and learning style: A twelve-year longitudinal study of UK medical graduates.

365

BMC Medical Education 2004; 2(29). doi;10.1186/1741-7015-2-29.

366

367

6. Rogers ME, Creed PA, Searle J. Person and environmental factors associated with well-being 368 in medical students. Personality and Individual Differences 2012; 52(4): 472-477.

369

370

7. Doherty EM, Nugent E. Personality factors and medical training: a review of the literature.

371 Medical Education 2011; 45(2):132-40.

372

373 8. Hojat M, Erdman JB, J. Gonnella. Personality assessment and outcomes in medical education 374 and the practice of medicine: AMEE Guide No. 79. Medical Teacher 2013;DOI:

375 10.3109/0142159X.2013.785654:1-35.

376 
377 9. Hojat M, Gonnella JS, Erdmann JB, Vogel WH. Medical students' cognitive appraisal of 378 stressful life events as related to personality, physical well-being, and academic performance: a 379 longitudinal study. Personality and Individual Differences 2003; 35:219-235.

380

381 10. Haight S, Chibnall JT, Schindler DL. Associations of medical student personality and 382 health/wellness characteristics with their medical school performance across the curriculum. 383 Academic Medicine 2012; 87(4):476-485.

384

385

11. Lievens F, Coetsier P, De Fruyt F, Maeseneer D. Medical students' personality characteristics 386

387 36(11):1050. and academic performance: a five-factor model perspective. Medical Education 2002;

388

389

390

12. Ferguson E, James D, Madeley L. Factors associated with success in medical school:

391

392

393 systematic review of the literature. BMJ 2002;324.

394

395

396

13. McManus C, Powis D. Testing medical school selection tests. Medical Journal of Australia 2007; 186(3):118-9.

15. Ferguson E, James D, O'Hehir F, Sanders A. Pilot study of the roles of personality, references and personal statements in relation to performance over the five years of a medical 401 degree. BMJ 2003; 326:429-432.

402

16. Hojat M, Callahan C, Gonnella JS. Students' personality and ratings of clinical competence 404 in medical school clerkships: a longitudinal study. Psychological Health \& Medicine 2004; 405 9:247-252.

406 
407 17. Hojat M, Axelrod D, Spandorfer J, Mangione S. Enhancing and sustaining empathy in 408 medical students. Medical Teacher 2013; 35:996-1001.

409

410 18. Hojat M, Mann D, Massello D, Calabrese LH. Overlap between empathy, teamwork and 411 integrative approach to patient care. Medical Teacher 2014; Early Online:1-4. doi:

$41210.3109 / 0142159 X .2014$.

413

414 19. Diener E, Lucas RE. Personality and subjective well-being. In D. Kahnemann, E. Diener, \& 415 N. Schwarz (Eds.), 1999. The foundations of hedonic psychology. 213-229. New York: Russell 416 Sage.

417

418 20. Haslam N, Whelan J, Bastian B. Big five traits mediate associations between values and 419 subjective well-being. Personality and Individual Differences 2009; 46:40-2.

420

421 21. Horsburgh VA, Schermer JA, Veselka L, P. V. A behavioural genetic study of mental 422 toughness and personality. Personality and Individual Differences 2009; 46:100-5. 423

22. Borges NJ, Osmon WR. Personality and medical specialty choice: technique orientation 425 versus people orientation. Journal of Vocational Behaviour 2001; 58(1):22-35. 426

23. Hojat, M. Zuckerman M. Personality and specialty interest in medical students. Medical 428 Teacher 2008; 30(4):400 - 406.

429

24. Duffy RD, Borges N, Harthung P. Personality, Vocational Interests, and Work Values of 431 Medical Students. Journal of Career Assessment 2009; 17:189.

432

433 25. Costa PT, McCrae RR. Revised NEO Personality Inventory (NEO-PI-R) and NEO Five 434 Factor Inventory (NEO-FFI) Professional Manual. 1992; Odessa, Florida: Psychological 435 Assessment Resources. 
437 26. Tyssen RD, Rovik FC, Thorkildsen JO, Ekeberg RT, Hem O, Gude T, Gronbold NT,

438 Baglum, P. Personality traits and types predict medical school stress: a six year longitudinal and 439 nationwide study. Medical Education 2007; 4:781-787.

440

441

442

27. Knights JA, Kennedy BJ. Medical school selection: impact of dysfunctional tendencies on academic performance. Medical Education. 2007; 41(4):362-368.

443

444

28. Cloninger CR, Svrakic DM, Pryzbeck TR. A psychobiological model of temperament and 445 character. Archives of General Psychiatry 1993; 50:975-990.

446

447

29. Cloninger CR, Svrakic DM, Wetzel RD. The temperament and character inventory: A guide 448 to its development and use. 1994; St Louis, Missouri: Center for Psychobiology of Personality, 449 Washington University in St Louis.

450

30. Tanaka K, Mizuno K, Fukuda s, Tajima S, Watanabe Y. Personality traits associated with 452 intrinsic academic motivation in medical students. Medical Education 2009; 43:384-7. 453

31. Jiang N, Sato T, Hara T, Takedomi Y, Ozaki I, Yamada S. Correlations between trait anxiety, 455 personality and fatigue: Study based on the Temperament and Character Inventory. Journal of 456 Psychosomatic Research 2003; 55(6):493-500. doi: Doi: 10.1016/s0022-3999(03)00021-7.

32. Eley DS, Cloninger CR, Walters L, Laurence C, Synnott R. Wilkinson, D. The relationship 459 between resilience and personality traits in doctors: implications for enhancing well-being. PeerJ. 2013; 1(e216):1-16. doi: DOI 10.7717/peerj.216.

33. Cloninger CR, Zohar AH. Personality and the perception of health and happiness. Journal of 464 Affective Disorders. 2011; 128(1-2):131-134. being. The International Journal of Person Centred Medicine 2012; 2(1):1-9. 
468 35. Sievert M, Zwir I, Cloninger KM, Lester N, Rozsa S, Cloninger CR. The influence of 469 temperament and character profiles on specialty choice and well-being in medical residents.

470 PeerJ. 2016; 4:e2319;DOI 10.7717/peerj.2319.

471

472 36. Grucza RA, Goldberg LR. The comparative validity of 11 modern personality inventories:

473 predictions of behavioral acts, informant reports, and clinical indicators. Journal of Personality

474 Assessment 2007; 89(2):167-87.

475

476

37. Eley DS, Leung J, Hong B, Cloninger K, Cloninger CR. Identifying the Dominant

477 Personality Profiles in Medical Students: Implications for Their Well-Being and Resilience.

478 PLoS ONE. 2016; 11(8): e0160028. doi:10.1371/journal.pone.0160028

479

480 38. Howe A, Smajdor A, Stockl A. Towards an understanding of resilience and its relevance to 481 medical training. Medical Education 2005; 46:349-356.

482

483 39. Geller G. Tolerance for ambiguity: an ethics-based criterion for medical student selection.

484 Academic Medicine 2013; 88: 581-584.

485

486 40. Enns MW, Cox BJ, Sareen J, Freeman Adaptive and maladaptive perfectionism in medical 487 students: a longitudinal investigation. Medical Education 2001; 35:1034 1042.

41. Budner S. InTolerance of Ambiguity as a personality variable. Journal of Personality1962;

490

30:29-50

491

492

42. Caulfield M, Andolsek K, Grbic D, Roskovensky L. Ambiguity tolerance of students

493

matriculating to U.S. medical schools. Academic Medicine 2014; 89(11):1526-1532.

494

495 43. Cooke GP, Doust JA, Steele MC. A survey of resilience, burnout, and tolerance of

496 uncertainty in Australian general practice registrars. BMC Med Education 2013; 13: 2. 
498

499

500

501

502

503

504

505

506

507

508

509

510

511

512

513

514

515

516

517

518

519

520

521

522

523

524

525

526

527

44. Sherrill WW. Tolerance of ambiguity among MD/MBA students: Implications for management potential. Journal of Continuing Education for Health Professions 2001; 21:11171122.

45. Wayne S, Dellmore D, Serna L, Jerabek R, Timm C, Kalishman S. The association between inTolerance of Ambiguity and decline in medical students' attitudes towards the underserved. Academic Medicine 2011; 86:877-882.

46. Bachman K, Freeborn DK. HMO physicians' use of referrals. Social Science in Medicine 1999; 48(4):547-557.

47. Kuhn G, Goldberg R, Compton S. Tolerance for uncertainty, burnout, and satisfaction with the career of emergency medicine. Annals of Emergency Medicine 2009; 54:106-113.e106.

48. West C, Tan AD, Habermann TM, Sloan, JA, Shanafelt, TD. Association of resident fatigue and distress with perceived medical errors. JAMA 2009; 302(12): 1294-1300.

49. Schneider AWM, Linde K, Buhner M. Communicating and dealing with uncertainty in general practice: The association with neuroticism. PLOS ONE 2014; 9;7 e102780):1-7.

50. Feinmann J. Disruptive doctors are often found to be perfectionists. BMJ 2011; 342: (d876).

51. Peters M, King K. Perfectionism in doctors. BMJ 2012; 3 34:(e1674).

52. Flett G, Hewitt PL. Perfectionism: theory, research and treatment. American Psychological Association. 2002; 464.

53. Frost R, Marten $\mathrm{P}$, Lahart $\mathrm{C}$, Rosenblate $\mathrm{R}$. The dimensions of perfectionism. Cognitive Therapy \& Research 1990; 14:449-468. 
528 54. Cloninger C., Zohar AH, Hirschmann S, Dahan D. The psychological costs and benefits of 529 being highly persistent: Personality profiles distinguish mood disorders from anxiety disorders. 530 Journal of Affective Disorders 2012; 136:758-766.

531

532 55. Mclain DI. Evidence of the properties of an ambiguity tolerance measure: the Multiple 533 Stimulus Types Ambiguity Tolerance Scale-II (MSTAT-II). Psychological Reports 2009; 105; 3 : 534 975-988. doi: 10.2466/pr0.105.3.975-988

535

536 56. Stallman HM. The factor structure of the Frost Multidimensional Perfectionism Scale in 537 University Students. Australian Psychologist 2011; 1-8. doi: 10:1111/j.1742-9544.2010.00010.x. 538

539 57. Epstein RM, Krasner, MD. Physician Resilience: What It Means, Why It Matters, and How 540 to Promote It. Academic Medicine 2013; 88(3): 301-303.

541

542 58. Krasner MS, Epstein RM, Beckman H, Suchman AL, Chapman B, Mooney CJ, Quill TE. 543 Association of an educational program in mindful communication with burnout, empathy, and 544 attitudes among primary care physicians. JAMA 2009; 302(12):1284-1293.

545

546 59. Campanella FC, Crescentini C, Urgesi. Fabbro F. Mindfulness-oriented meditation improves 547 self-related character scales in healthy individuals. Comprehensive Psychiatry 2014; 55(5):12695481278.

549 


\section{Table $\mathbf{1}$ (on next page)}

Table 1: Descriptive statistics of the whole sample $(\mathrm{N}=808)$ 
1

2

3

4

\section{5}

Table 1:

Descriptive statistics of the whole sample $(N=808)$.

\begin{tabular}{|c|c|c|}
\hline & $\mathbf{n}$ & $\%$ \\
\hline \multicolumn{3}{|l|}{ Age } \\
\hline Under 25 years & 443 & 54.8 \\
\hline 25 or older & 349 & 43.2 \\
\hline \multicolumn{3}{|l|}{ Gender } \\
\hline Male & 439 & 54.3 \\
\hline Female & 368 & 45.5 \\
\hline \multicolumn{3}{|l|}{ Year medical school } \\
\hline Year 1 & 599 & 74.1 \\
\hline Year 2 & 75 & 9.3 \\
\hline Year 3 & 67 & 8.3 \\
\hline Year 4 & 66 & 8.2 \\
\hline \multicolumn{3}{|l|}{ TCI personality profile $\dagger$} \\
\hline Profile 1 & 483 & 59.8 \\
\hline Profile 2 & 325 & 40.2 \\
\hline Coping mechanisms & Mean & SD \\
\hline Tolerance of Ambiguity & 43.55 & 7.58 \\
\hline Maladaptive perfectionism (concern over mistakes) & 20.63 & 6.14 \\
\hline Adaptive perfectionism (high standards) & 18.46 & 3.84 \\
\hline \multicolumn{3}{|c|}{$\begin{array}{l}\dagger \text { Profile } 1 \text { was characterized by low to average levels of Harm Avoidance, and high to very } \\
\text { high levels of Persistence, Self-Directedness and Cooperativeness. Profile } 2 \text { was characterized } \\
\text { by average-high levels of Harm Avoidance and high levels of Persistence, Self-Directedness } \\
\text { and Cooperativeness }\end{array}$} \\
\hline
\end{tabular}




\section{Table 2 (on next page)}

Table 2: Table of independent t-tests results of Tolerance of ambiguity and Perfectionism by age, gender and year of study $(\mathrm{N}=808)$. 
1

2 Table 2

3 Table of independent t-tests results of Tolerance of ambiguity and Perfectionism by age, 4 gender and year of study $(\mathrm{N}=808)$.

5

\begin{tabular}{|c|c|c|c|c|c|c|}
\hline & \multicolumn{2}{|c|}{$\begin{array}{l}\text { Tolerance of } \\
\text { Ambiguity }\end{array}$} & \multicolumn{2}{|c|}{$\begin{array}{c}\text { Perfectionism - } \\
\text { Concern over mistakes }\end{array}$} & \multicolumn{2}{|c|}{$\begin{array}{l}\text { Perfectionism - High } \\
\text { Standards }\end{array}$} \\
\hline & Mean & SD & Mean & SD & Mean & SD \\
\hline \multicolumn{7}{|l|}{ Age } \\
\hline Under 25 years & 42.85 & 7.14 & 20.50 & 6.02 & 18.14 & 3.93 \\
\hline \multirow[t]{2}{*}{25 or older } & 44.42 & 8.09 & 20.78 & 6.36 & 18.93 & 3.67 \\
\hline & \multicolumn{2}{|c|}{$\begin{array}{c}\mathrm{t}=2.90, \mathrm{p}=0.004 \\
\text { eta-sq }=0.01\end{array}$} & \multicolumn{2}{|c|}{$\begin{array}{c}\mathrm{t}=0.63, \mathrm{p}=0.530 \\
\text { eta-sq }=0.00\end{array}$} & \multicolumn{2}{|c|}{$\begin{array}{c}\mathrm{t}=2.89, \mathrm{p}=0.004 \\
\text { eta-sq }=0.01\end{array}$} \\
\hline \multicolumn{7}{|l|}{ Gender } \\
\hline Male & 44.23 & 7.40 & 20.08 & 6.01 & 18.26 & 3.90 \\
\hline \multirow[t]{2}{*}{ Female } & 42.74 & 7.73 & 21.28 & 6.25 & 18.71 & 3.77 \\
\hline & \multicolumn{2}{|c|}{$\begin{array}{c}\mathrm{t}=2.78, \mathrm{p}=0.006 \\
\text { eta-sq }=0.01\end{array}$} & \multicolumn{2}{|c|}{$\begin{array}{c}\mathrm{t}=2.77, \mathrm{p}=0.006 \\
\text { eta-sq }=0.01\end{array}$} & \multicolumn{2}{|c|}{$\begin{array}{c}\mathrm{t}=1.64, \mathrm{p}=0.101 \\
\text { eta-sq }=0.00\end{array}$} \\
\hline \multicolumn{7}{|l|}{ Year medical school } \\
\hline Year 1 & 43.82 & 7.64 & 20.38 & 5.92 & 18.54 & 3.93 \\
\hline Year 2 & 43.67 & 7.35 & 21.10 & 6.96 & 18.04 & 3.36 \\
\hline Year 3 & 42.04 & 7.15 & 20.81 & 5.92 & 18.43 & 3.84 \\
\hline \multirow[t]{2}{*}{ Year 4} & 42.14 & 7.25 & 22.23 & 7.24 & 18.29 & 3.62 \\
\hline & \multicolumn{2}{|c|}{$\begin{array}{c}\mathrm{t}=1.39, \mathrm{p}=0.123 \\
\text { eta-sq }=0.01\end{array}$} & \multicolumn{2}{|c|}{$\begin{array}{c}\mathrm{t}=1.41, \mathrm{p}=0.114 \\
\text { eta-sq }=0.01\end{array}$} & \multicolumn{2}{|c|}{$\begin{array}{c}\mathrm{t}=0.66, \mathrm{p}=0.729 \\
\text { eta-sq }=0.00\end{array}$} \\
\hline
\end{tabular}

6

7 


\section{Table 3 (on next page)}

Table 3: Generalized linear models with the main effects of personality profilest and its interaction with age and gender on tolerance of ambiguity and perfectionism 
1

Table 3

Generalized linear models with the main effects of personality profiles $\dagger$ and its interaction with age and gender on tolerance of ambiguity and perfectionism

\begin{tabular}{|c|c|c|c|}
\hline & $\mathbf{B}$ & SE & $\mathbf{p}$ \\
\hline \multicolumn{4}{|l|}{ Model 1: Tolerance of ambiguity } \\
\hline Personality profile & 7.42 & 0.96 & $<0.001$ \\
\hline Age & -0.21 & 0.78 & 0.789 \\
\hline Gender & 1.26 & 0.77 & 0.103 \\
\hline Personality profile $\mathrm{x}$ Age interaction & -2.33 & 1.00 & 0.020 \\
\hline Personality profile $\mathrm{x}$ Gender interaction & 0.58 & 1.00 & 0.564 \\
\hline \multicolumn{4}{|c|}{ Model 2: Maladaptive perfectionism (concern over mistakes) } \\
\hline Personality profile & -5.11 & 0.80 & $<0.001$ \\
\hline Age & 1.24 & 0.65 & 0.056 \\
\hline Gender & -1.18 & 0.64 & 0.068 \\
\hline Personality profile $\mathrm{x}$ Age interaction & 1.12 & 0.84 & 0.182 \\
\hline Personality profile $\mathrm{x}$ Gender interaction & -0.34 & 0.83 & 0.681 \\
\hline \multicolumn{4}{|c|}{ Model 3: Adaptive perfectionism (high standards) } \\
\hline Personality profile & 1.10 & 0.52 & 0.035 \\
\hline Age & 1.28 & 0.43 & 0.003 \\
\hline Gender & -0.36 & 0.42 & 0.393 \\
\hline Personality profile $\mathrm{x}$ Age interaction & 0.90 & 0.55 & 0.099 \\
\hline Personality profile $\mathrm{x}$ Gender interaction & -0.11 & 0.54 & 0.845 \\
\hline \multicolumn{4}{|c|}{$\begin{array}{l}\text { Note. Reference groups in the models were personality profile 2, under } 25 \text { years age group, } \\
\text { and female gender. } \\
\text { †Profile } 1 \text { was characterized by low to average levels of Harm Avoidance, and high to very } \\
\text { high levels of Persistence, Self-Directedness and Cooperativeness. Profile } 2 \text { was } \\
\text { characterized by average-high levels of Harm Avoidance and high levels of Persistence, } \\
\text { Self-Directedness and Cooperativeness }\end{array}$} \\
\hline
\end{tabular}


Figure $\mathbf{1}$ (on next page)

Figure 1 - The two personality profiles classified based on the seven $\mathrm{TCl}$ subscales $(\mathrm{N}=$ 808) 


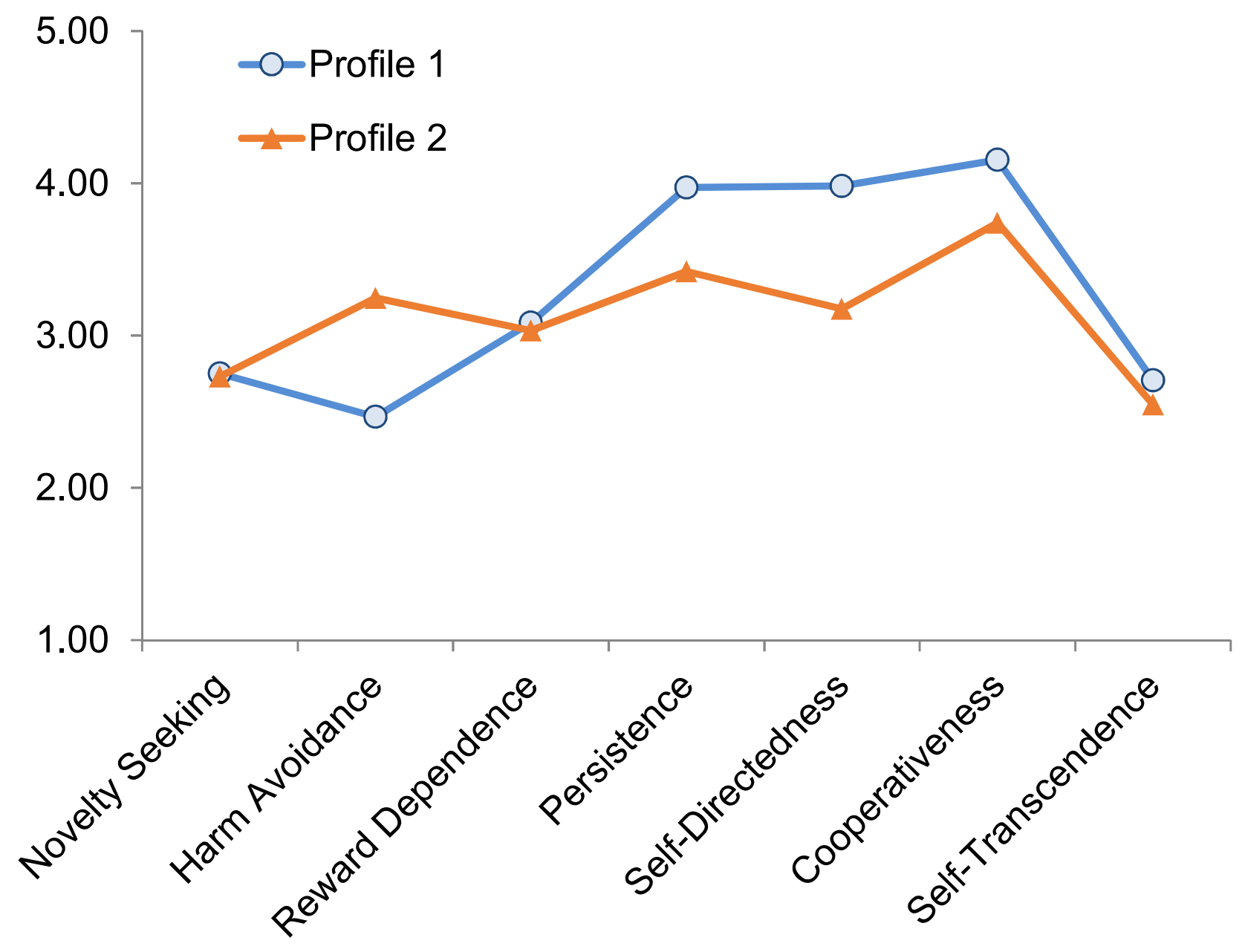


Figure 2 (on next page)

Levels of ambiguity tolerance and perfectionism by the two personality profiles $(\mathrm{N}=$ 808)

Students with the Profile 1 had significantly higher levels of Tolerance of Ambiguity ( $t=12.73$, $\eta=.58, p<.001$ ), Perfectionism-High Standards ( $t=6.02$, $<$ !--[if !supportLists]-- $>250<$ !-[endif]-- $>\eta=.21, p<.001$ ), and lower levels of Perfectionism-Concern over Mistakes ( $t=-11.19$, $\eta=.37, p<.001)$. 


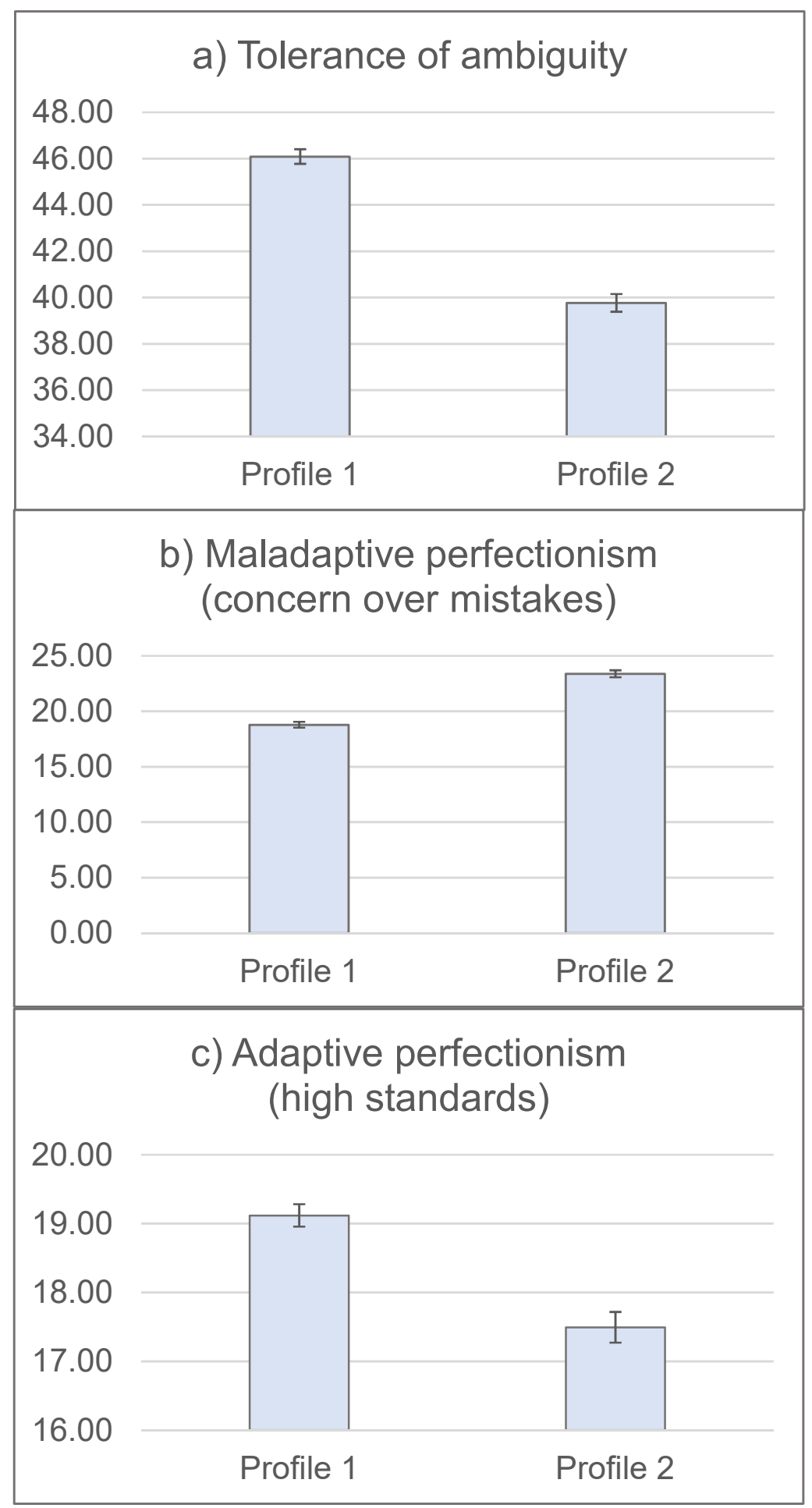


Figure 3 (on next page)

Figure 3 - Interaction effects of personality profile and age on tolerance of ambiguity 


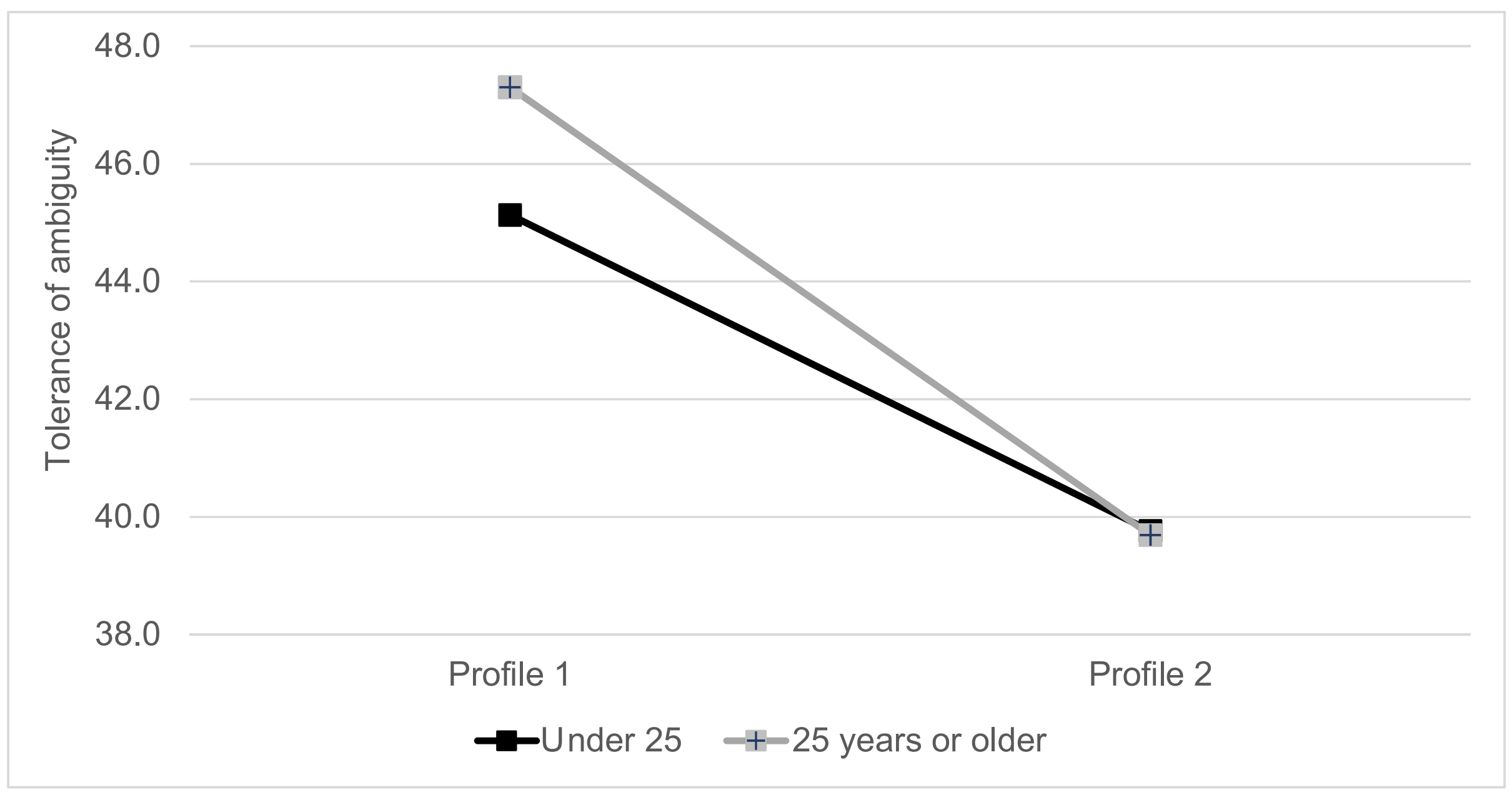

